\title{
COMBATES| Epigrafe
}

\section{ABOLIÇÃO BRITÂNICA: PARADIGMAS E HISTORIOGRAFIAS}

\section{Pedro Giovannetti Moura*}

Resumo: O presente artigo visa introduzir o leitor ao amplo debate historiográfico sobre a Abolição Britânica. Apesar de seu início no Século XIX, foi somente com a publicação de "Capitalismo e Escravidão" de Eric Williams, em 1944, que o debate ganhou suas feições atuais: a polarização entre a visão historiográfica estruturalista, da qual é Williams seu grande precursor contrapor-se-ia à perspectiva culturalista que buscaria no humanitarismo Britânico a causa central para explicar a Abolição. Para atingir tal intento, o artigo analisa de forma comparativa quatro livros: "The American Crucible" de Robin Blackburn, "Abolição: uma História da escravidão e do antiescravismo" de Seymour Drescher, "Os Jacobinos Negros" de Cyril Lionel Robert James e o já citado "Capitalismo e Escravidão" de Eric Williams.

Palavras-chave: Abolição; Historiografia; Colônia; Escravismo.

Quando, em 1944, Eric Williams publicou sua obra "Capitalismo e escravidão", o autor estava criando um novo paradigma de análise da escravidão do Novo Mundo e também inaugurando um debate historiográfico cuja duração se estenderia até os dias atuais.

Debate este que será o tema desse estudo, o qual buscará proporcionar uma síntese da historiografia sobre a Escravidão e, principalmente, entender os diferentes pontos de vista existentes acerca de sua abolição, cujas datas diferem em diferentes partes do mundo, focando-se principalmente em quatro autores: o já mencionado Eric Williams, Cyril Lionel Robert James, Seymour Drescher e Robin Blackburn, os quais, apesar de estarem distantes de abarcar a totalidade desse debate, apresentam um importante rompimento de modelos pré-existentes (nos dois primeiros casos) e uma nova abordagem (nos dois últimos), abordagens estas que, apesar de radicalmente distintas, representam uma síntese e um acréscimo de duas linhas de pensamento conflitantes.

\footnotetext{
* Graduação em História pela Universidade de São Paulo - USP.
} 


\section{COMBATES Epigrafe}

PEDRO GIOVANNETTI MOURA

Como já dito, a obra de Eric Williams apresentou um rompimento de paradigmas de análises pré-existentes, representados principalmente pela chamada Escola Imperial Britânica, cujos ícones foram J. R. Seeley e R. Coupland.

A Escola Imperial Britânica tratou-se da primeira tentativa historiográfica de explicações sobre escravidão e abolição separada de interesses imediatistas; antes da Escola Imperial o debate era conduzido por proprietários e "anti-proprietários" que encontravam na produção histórica um meio de lobby visando seus interesses. J. R. Seeley, em 1883,inicia o debate trazendo à tona o atualmente conhecido conceito da predisposição climática dos africanos ao trabalho nos trópicos; $R$. Coupland, em 1933, vai além, explicando a abolição britânica, em 1833, como sendo fruto exclusivo de um humanitarismo britânico. Aliado à concepção comteana progressista da humanidade, teriam então os britânicos um fardo, o chamado fardo do homem branco, de levar seus progressos humanísticos às nações mais atrasadas, não civilizadas.

Tanto o discurso de Seeley como o de Coupland são reflexos e contribuem como contexto da época de expansão europeia; uma nova explicação não poderia surgir no meio europeu, envolvido quase em sua totalidade com um imperialismo expansionista.

Retornamos assim ao começo do estudo: em 1944, com Eric Williams, nascido em Trinidad e Tobago e graduado em Oxford. O conteúdo de seu livro é a primeira parte de uma resposta caribenha ao método interpretativo então vigente.

Esquemática, a obra de Williams soa como um manual, o que de fato não constitui uma mentira, apesar de seu atual reconhecimento em meios acadêmicos. Escrita por um caribenho que mais tarde tornar-se-ia primeiro ministro de seu país, a obra estava envolvida em um forte contexto político de independência antilhana. Assim, o livro funcionou como uma espécie de manual para ativistas do movimento independentista caribenho, inclusive ao próprio autor.

Talvez,explicar a obra seja possível valendo-se de três eixos-chave, tendo em Marx o ponto de partida para estes. Em um primeiro momento, Williams vale-se da interpretação do racismo funcional, isto é, que o racismo seria fruto de uma questão de classe, contrariando assim Seeley, que com sua teoria climática deixava claro o 


\section{COMBATES Epigrafe}

ABOLIÇÃO BRITÂNICA: PARADIGMAS E HISTORIOGRAFIAS

conceito de raça. As duas demais teorias são um ataque direto às premissas culturalistas de Coupland. Explicando a escravidão sob um prisma econômico, Williams a considera, principalmente através do estudo do tráfico negreiro, amplamente exercido pela Inglaterra no século XVIII, o meio central à acumulação primitiva de capital, fundamental para a adoção de uma política de créditos e consequentemente ao desenvolvimento da Revolução Industrial. Daí temos a relação que nomeia o título de seu livro, isto é, a escravidão como instituição base à formação do capitalismo.

O último aspecto analisado pelo autor foi a abolição da escravidão, em 1833. Segundo Williams, a Revolução Americana tornou o Caribe Inglês um empreendimento insustentável à metrópole, pois além de serem as treze colônias fornecedoras de artigos de suma importância à manutenção do Caribe Inglês, dentre os quais destacavam-se pescados, principalmente o Bacalhau salgado, que passou a ser livremente negociado com o Caribe Francês, tornando a produção do açúcar de São Domingo (principal colônia francesa) ainda mais barata do que a do Inglês; o monopólio comercial tornara-se, assim, inviável do ponto de vista metropolitano, sendo defendido apenas por lobby de senhores de escravos absenteístas, os quais gozavam de grande influência no parlamento britânico.

A extinção do monopólio comercial tornou-se de vital importância à metrópole. Dar-se-ia assim uma ordem de ataque: primeiro o fim do tráfico, seguido do fim da escravidão e do fim do monopólio.

Em 1807,a Inglaterra, visando uma queda econômica de São Domingo, grande produtora francesa e sofrendo com a pressão dos senhores de suas colônias mais antigas, tais como a Jamaica e Barbados, os quais não queriam seus produtos competindo com os produtos das colônias recentemente incorporadas ao Império britânico com a Guerra dos Sete Anos, Guadalupe e Martinica, nem com os brasileiros, cubanos e estadunidenses,suspende o tráfico escravo.

A segunda etapa, o fim da escravidão, marca o choque entre comerciantes, defensores da instituição escrava e industrialistas, que viam no fim da escravidão um meio de enfraquecimento do poder dos senhores caribenhos, visando sempre a quebra do monopólio. Assim, no décimo primeiro capítulo da obra, temos um 


\section{COMBATES Epigrafe}

PEDRO GIOVANNETTI MOURA

ataque direto a Coupland, quando Williams associa as petições abolicionistas aos interesses industrialistas, sendo por estes patrocinados. O silêncio sobre a distribuição de terras, sobre os produtos estadunidenses, brasileiros e cubanos (produzidos por escravos), além do racismo contra os negros, seriam, na visão do autor, argumentos que determinariam o caráter central da abolição: econômica, não humanitária; as manifestações da sociedade civil inglesa não passariam assim de mera hipocrisia.

No capítulo seguinte, Williams, após praticamente ter terminado seu livro, marcado por um forte economicismo, menciona as revoltas escravas de Barbados, em 1816, de Demerara, em 1823 e da Jamaica, em 1831, como fator importante na abolição. Contudo, será em C.L.R. James que, adiante, veremos a participação escrava de forma mais esmiuçada no processo de abolição.

Por fim, a terceira etapa deu-se em 1846, com o fim do monopólio comercial Britânico com as índias ocidentais, permitindo dessa maneira aos industrialistas que aplicasse a ideologia de livre mercado.

Inicialmente, a obra de Williams não foi sequer mencionada nos meios acadêmicos, principalmente nos ingleses, já que desconstruíra a ideia do humanitarismo britânico, dando a estes um papel de opressores na escravidão, não de libertadores, como pleiteava-se. Contudo, seu sucesso posterior inaugurou uma série de debates, os quais estender-se-iam pelo século XX. As críticas foram diversas e serão analisadas adiante, usando-se como principal expoente Seymour Drescher. Entretanto, impossível é terminar essa breve análise da obra de Eric Williams sem mencionar sua importância.

Além de inaugurar um debate vivo até hoje no meio historiográfico, Williams foi responsável pela construção de um conceito chave, inclusive para a historiografia brasileira: o de Sistema Atlântico. Colônia e metrópole estariam relacionadas através de vínculos assimétricos de poder em um sistema que visava o lucro da segunda. No Brasil, temos sobretudo em Fernando Novais essa transposição do conceito de Sistema Atlântico do Caribe para o Brasil.

Publicada anos antes, em 1938, temos a obra de Cyril Lionel Robert James, "Os Jacobinos Negros".Amigo de Williams, James viveu com este na Inglaterra, onde 


\section{COMBATES Epigrafe}

ABOLIÇÃO BRITÂNICA: PARADIGMAS E HISTORIOGRAFIAS

participou de grupos políticos trotskistas, anos antes de ir à França trabalhar em sua tese central: a Revolução Haitiana.

Inicialmente, salta aos olhos do leitor a forma de escrita de James, radicalmente distinta da de Williams. Se no segundo temos um cunho esquemático, no primeiro destaca-se a escrita mais narrativa, o que reflete também os distintos caminhos tomados por esses dois importantes autores. Enquanto Williams, como já dito, seguiu o meio acadêmico e tornou-se mais tarde o primeiro ministro de Trinidad e Tobago, James foi sempre um militante político envolvido com as causas do pan-africanismo.

Diferenças à parte, as quais demandariam um trabalho mais específico de estudo comparativo entre as obras dos autores, temos na obra de James um complemento à de Williams, já que, apesar de publicada anos antes, pode-se dizer que ambos os estudos foram produzidos no mesmo período.

Iniciando a obra com um relato contundente da escravidão e percorrendo as planícies de São Domingo, James proporciona um ótimo trabalho de síntese dos acontecimentos revolucionários. Apesar do protagonismo escravo em sua revolução e em sua luta por seus próprios destinos, James valeu-se da dialética marxista, assim como Williams, para explicar a revolução de São Domingo como uma consequência natural das contradições e tensões sociais. Contudo, duas importantes diferenças são notadas. A primeira delas é a questão racial. Apesar de sua interpretação marxista do racismo como uma consequência essencialmente da luta de classes, James não deixa de considerar a questão racial como um importante componente revolucionário. A questão dos mulatos como uma força de tensão em uma sociedade extremamente racializada quanto a sua divisão é constantemente abordada, como quando se tem dois focos de revolta, um, mulato, liderado por Rigaud e outro, negro, liderado por Toussaint. O papel dos brancos pobres como fator de tensão também é abordado pelo autor.

A segunda diferença para Williams está na participação das massas no processo revolucionário. Enquanto este, em seu livro, menciona o papel das massas para abolição da escravidão em apenas um capítulo - acrescido de última hora pelo autor, James, ao longo de seu livro, apresenta uma atuação direta das massas no 


\section{COMBATES Epigrafe}

PEDRO GIOVANNETTI MOURA

processo revolucionário mesmo sem partido revolucionário e que, apesar de tratar de um episódio diferente, contém um posicionamento radicalmente distinto do de Williams.

Por fim, vale também citar a busca de James por tornar a Revolução Haitiana um fenômeno aceito e próximo ao europeu. Primeiramente, isto se deu com o próprio título de sua obra e seu significado ao longo desta. Ao colocar os escravos como combatentes que buscavam pertencer à Nação Francesa e chamá-los de jacobinos, o autor os está aproximando do mundo europeu. E, ao retratar o líder revolucionário - Toussaint L'ouverture - como um líder que visou sempre o contato harmonioso entre brancos e negros, o autor buscou quebrar o paradigma de que fora a revolução um genocídio branco.

Em 1977, Seymour Drescher publicava sua primeira manifestação nesse debate com a publicação de "Econocide". O desenho de sua obra já é suficiente para o entendimento de seu ponto teórico chave. A obra de Drescher consiste em uma compilação de assertivas de Williams, seguidas por comentários críticos seus. Em uma de suas críticas,o autor alega que após 1790 temos o zênite do tráfico britânico. Logo, sua abolição consistiria um suicídio econômico.

Em 2009, foi publicada a mais recente obra de Seymour Drescher, "Abolição: uma história da escravidão e do antiescravismo". David Eltis e seu conceito de não escravização de sua própria comunidade e Roger Ansrey e sua teoria da participação das seitas anglicanas batistas e metódicas parecem ter sido os dois pontos de partida do autor.Assim como a Escola Imperial, Drescher assume a abolição como uma manifestação culturalista. No entanto, para isso, vale-se de novos conceitos e críticas ao modelo puramente econômico de Williams.

A primeira parte de seu livro apresenta em seu título ("A extensão”)o mecanismo pelo qual o autor se valerá para defender sua teoria. A escravidão seria, segundo Drescher, uma instituição perene, isto é, presente desde a Antiguidade até a era Contemporânea, além de universal. E, ao trazer uma estruturação cronológica de seu livro, o autor não só falará brevemente das escravidões antigas, como abordará a escravidão branca no Magreb, tão forte como a atlântica e o retorno da 


\section{COMBATES Epigrafe}

ABOLIÇÃO BRITÂNICA: PARADIGMAS E HISTORIOGRAFIAS

escravidão com os regimes totalitários do século XX, em especial o caso soviéticocomunista e o caso alemão-nazista.

Seria então a Inglaterra apenas mais uma a praticar a escravidão, apresentando, contudo, uma importante diferença em relação às demais sociedades escravistas: a existência de uma esfera pública em sua sociedade. O caso do escravo James Somerset é então amplamente abordado. Escravo de um proprietário virginiano, ao visitar a Inglaterra, James Somerset tem contato com abolicionistas britânicos que, valendo-se do direito segundo o qual quem pisa na Inglaterra torna-se livre (oriundo do direito consuetudinário inglês), instruem o escravo a lutar por sua liberdade.O caso ganha então um contorno público, com espaço em jornais, participação de associações voluntárias e petições públicas. James Somerset é então absolvido por Mansfield, juiz do caso.

A sociedade civil inglesa explode então em diversas manifestações e petições públicas pelo fim do tráfico, tendo inclusive as mulheres papel fundamental não só na assinatura de petições, como também no boicote à compra de produtos cuja origem era o trabalho escravo. Além delas, merecem destaque, segundo o autor, as seitas Quaker, grandes contestadoras da instituição escrava.

A existência de uma esfera pública, que não poderia surgir em um país com ligações ao Mediterrâneo - por tratar-se de um espaço com a escravidão latente -, levou a Inglaterra a uma transformação cultural, que propiciou uma autoanálise moral da sociedade. E foi justamente essa autonomia em relação ao Estado que proporcionou a contestação da escravidão na Inglaterra. A escravidão é universal, segundo Drescher, já sua contestação é fruto de uma sociedade com o caráter essencialmente burguês, contrariando assim totalmente a teoria de Williams, segundo a qual os ideais burgueses não só foram os responsáveis pela escravidão, como não tiveram participação em sua abolição, a qual teria um sentido exclusivo de lucro'.

\footnotetext{
${ }^{1}$ Daí entendemos a escolha de Drescher de falar em escravidão nas sociedades totalitárias do século XX, sociedades estas desprovidas de autonomia pública, liberdade característica de sociedades burguesas.
} 


\section{COMBATES Epigrafe}

PEDRO GIOVANNETTI MOURA

Para provar sua teoria, Drescher vale-se de uma análise empírica dos lucros obtidos pelos ingleses com o tráfico de escravos e, como já dito anteriormente, esse lucro estava em seu ponto máximo. Aproximadamente $60 \%$ das vendas de escravos era conduzida por ingleses, mais da metade do açúcar era por eles produzido também. Além disso, foram os Estados Unidos o segundo país a abolir a escravidão, graças também às suas premissas culturais, herdadas dos ingleses. A pressão sobre os brasileiros e cubanos pelo fim do tráfico foi impulsionada, assim, exclusivamente por valores morais.

Entretanto podemos nos indagar: e a Revolução Americana? E a Revolução Industrial? E a participação das massas haitianas? A primeira não teve nenhum papel de fato, pois o panorama escravocrata não se alterou. Já a Revolução Industrial é citada apenas em uma única passagem do livro pelo autor, justamente ao criticar quem a defende como determinante para a abolição. O caso de São Domingo influi significativamente no processo abolicionista, segundo o autor, porém de forma negativa. O genocídio branco que foi a Revolução de São Domingo e seu radicalismo retardaram o processo abolicionista; a Dinamarca aumentou suas importações escravas e a Inglaterra respondeu com a tomada do Rio da Prata, importante porto comercial escravo no atlântico sul.

Apesar do fracasso que foi a revolta de São Domingo, temos em outras duas revoltas importantes acréscimos à batalha antiescravidão. Em Demerara, em 1823 e na Jamaica, em 1831-2, temos revoltas lideradas por missionários brancos, com destaque para os batistas na Jamaica. A resposta dos proprietários foi brutal: deram-se verdadeiros massacres nas revoltas, tornando a luta desses escravos

liderados por missionários uma cause célèbre. É, contudo, importante notar a diferença entre essas revoltas para a de São Domingo, pois as segundas, lideradas por missionários brancos, não foram massacres contra os brancos proprietários de terras.

Dessa forma Drescher considera a escravidão como uma característica universal e perene do ser humano, já o caso inglês, de existência de uma sociedade civil, constitui uma exceção, sendo os valores burgueses de liberdade, desenvolvidos nessa sociedade com vida própria em relação ao seu Estado, os 


\section{COMBATES Epirgrefe}

ABOLIÇÃO BRITÂNICA: PARADIGMAS E HISTORIOGRAFIAS

precursores dos direitos humanos. Com o pico do sistema econômico escravista coincidindo com a época abolicionista, contraria a tese de Williams da abolição como sendo puramente econômica; com a análise empírica das assinaturas das petições em massa, demonstra que essas não foram apenas assinadas por industrialistas, mostrando assim uma participação massiva da sociedade, não restringindo-se então a abolição a uma questão de classe.

Se em Seymour Drescher temos uma revitalização da perspectiva culturalista de R. Coupland e um ataque a Eric Williams, marxista, Robin Blackburn se insere nesse debate ao aproximar-se de Williams, dando uma nova roupagem à obra do autor.

Escrito em 2011 "The american Crucible: Slavery, Emancipation and Human Rights" ${ }^{2}$ é a obra mais recente do autor e, também, na que talvez melhor possa se visualizar o posicionamento de Blackburn.

Assim como em Drescher, iniciaremos a análise de seu livro com o título de sua primeira parte: "Plantation and Empire". A instituição plantation deu-se com a formação dos impérios Britânico e Francês no além-mar e tratava-se da instituição básica de domínio dessas metrópoles no Novo Mundo; a primeira parte mostra assim, de forma expressa em seu próprio título, a relação entre os conceitos de imperium e dominium ${ }^{3}$ nos impérios de plantation.

A especificação da escravidão inglesa e francesa é o componente chave de análise da primeira parte do livro. Se em Drescher temos por objetivo primordial demonstrar a universalidade e perenidade da escravidão, em Blackburn temos esse posto ocupado pela diferenciação das escravidões.

A escravidão britânica e francesa diferiu-se, em primeiro lugar, das antigas (gregas e romanas, por exemplo). Enquanto estas tratavam de uma dominação local, proporcionada por uma conquista, o tráfico negreiro proporcionou uma migração forçada em números sem precedentes na história. Em segundo lugar,

\footnotetext{
2 "Cadinho americano: Escravidão, Emancipação e Direitos Humanos" (Tradução livre).

${ }^{3}$ A relação entre os conceitos de imperium e dominium foi expressa pelo historiador Anthony Pagden, segundo o qual o primeiro tratava-se da soberania política sobre determinado território e o segundo tratava-se do direito de propriedade de determinado local. PADGEN, Anthony. Peoples and empires: A short history of European Migration, Exploration, and Conquest, from Greece to the Present. New York: Random House, 2001.
} 


\section{COMBATES Epigrefe}

PEDRO GIOVANNETTI MOURA

Blackburn responde diretamente a Drescher no que tange à escravidão islâmica. Esta distinguia-se da europeia por ser uma escravidão essencialmente militar, não agrícola; logo, a mobilidade social era maior nessas sociedades.

Por fim, o autor estabelece uma diferenciação entre as próprias escravidões europeias: de um lado, temos a escravidão barroca (portuguesa e espanhola); de outro, está a escravidão de plantation (francesa e inglesa). Enquanto na primeira o número de manumissões era maior, sendo assim a racialização não usada como um componente de dominação social, na segunda temos uma escravidão que valia-se das diferenças raciais para o exercício da dominação - as manumissões nos Impérios franceses e britânicos eram raríssimas. Assim, se em Portugal, por exemplo, temos uma proporção de um escravo para um negro livre para um branco, na Inglaterra e na França temos uma pequena elite local que controlava uma imensa maioria de trabalhadores negros, valendo-se de uma estrita diferenciação racial.

Nesse ponto, Blackburn apresenta um importante complemento à obra de Williams. Se para este o racismo tratava-se apenas de uma questão de classe, Blackburn nos mostra como este era usado para proporcionar uma exploração negra, visando sempre uma maior lucratividade, pautada em uma animalização do escravo. Este era dividido em bandos de trabalho, segundo sua idade e força. $\mathrm{Na}$ época de colheita, o trabalho dava-se também de noite e as jornadas chegavam a incríveis 18 horas diárias.

Na segunda parte de seu livro, Blackburn retoma a questão chave de Williams: a escravidão como uma instituição que proporcionou uma acumulação primitiva de capital para o desenvolvimento da indústria. Para tanto, Blackburn observa que a escravidão era 50\% mais rentável do que qualquer outro negócio; o erro de Williams foi sua restrição à análise apenas do tráfico em seu consagrado paradigma do comércio triangular, excluindo dessa forma o lucro propiciado pelas plantations. Assim, a instituição como um todo fora responsável pela construção de reservas financeiras, fundamentais para a doção de uma política creditária, fator determinante à Revolução Industrial.

Se, contudo, era a escravidão uma instituição extremamente rentável ao governo inglês, por que a abolição?É nesse ponto, talvez, que reside a grande 


\section{COMBATES Epigrafe}

ABOLIÇÃO BRITÂNICA: PARADIGMAS E HISTORIOGRAFIAS

qualidade da obra de Blackburn. Se até então estudamos autores que buscavam um caminho para sua explicação, desvalidando os demais, em Blackburn temos uma congruência de diversos fatores como responsáveis pela queda da escravidão, além de uma análise de causa e efeito muito mais desenvolvida, dando aos acontecimentos uma ligação entre si.

Deram-se mudanças. Em primeiro lugar, na mentalidade do homem europeu. Pela primeira vez na história a instituição escrava não era vista de uma forma natural ao ser humano. Rousseau e sua ideia do bom selvagem, a reimpressão da obra do dominicano Las Casas - contestador das atrocidades europeias em terras do Novo Mundo - e principalmente a sociedade civil inglesa, com a discussão do caso James Somerset em uma esfera pública, a participação de seitas anglicanas como os metodistas e batistas, acrescidas de ações de seres humanos, como Clarkson, cujo mérito é reconhecido até mesmo por Williams (que chamara a sociedade civil inglesa de hipócrita), fomentaram um contexto no qual críticas, em primeiro lugar ao tráfico, começaram a surgir.

Em segundo lugar, temos a Revolução Americana. Esta propaga ideais de liberdade, patriotismo, economia autossuficiente e existência de uma sociedade civil, as quais encorajam um verdadeiro arco de revoluções na América Latina, das quais uma em especial alteraria os rumos da escravidão: a Revolução Haitiana, que ocupa o terceiro e mais importante posto, na visão do autor, nessa série de mudanças.

Blackburn oferece, em primeiro lugar, uma interpretação marxista da Revolução, considerando-a um estágio natural da sociedade capitalista, aproximando-se assim de James e considerando-a ela própria a verdadeira criadora dos Direitos Humanos modernos.

Nesse ponto temos mais uma oposição do autor a Seymour Drescher. Se para este, os Direitos Humanos são criados na sociedade inglesa, a única genuinamente com valores burgueses até então, Blackburn transfere essa autoria às massas de São Domingo. Isso se deve ao fato de ter sido a Revolução - a luta das massas - a extensão dos direitos da Revolução Francesa para todos; apesar de anacrônica a 


\section{COMBATES Epigrafe}

PEDRO GIOVANNETTI MOURA

utilização desse tipo de conceituação para essa época, ela é, na visão do autor, a única forma de explicação aceitável para os eventos.

As Revoluções na América Espanhola, então em curso, radicalizaram-se com a Revolução em São Domingo, devido a um aparato ideológico e também militar proporcionado pela Revolução Caribenha. Nos Estados Unidos, por sua vez, o efeito é justamente o inverso: é o de temor. Temor pela chamada "haitianização", isto é, que os fenômenos de São Domingo se repetissem na sociedade estadunidense.

Além disso, a Revolução trouxe consequências à Inglaterra também. Derrotada no Caribe, como descrito no livro de James, o país perdeu sua grande chance de tornar-se uma potência escravista, que teria se dado em caso de sucesso na invasão de São Domingo, maior produtora mundial de açúcar. Com isso, a Inglaterra passou a buscar uma nova estratégia para o domínio mundial, encontrando na luta abolicionista uma nova bandeira, a bandeira de um capitalismo moral $^{4}$.

Apesar de tais mudanças no panorama mundial, segundo Seymour Drescher, a instituição escrava atingia o pico de sua produtividade na época da abolição. Por que então os ingleses foram adiante na abolição?Segundo Robin Blackburn, os dados empíricos de Drescher carecem de uma análise mais profunda. De fato, o lucro era maior, mas qual o motivo? Segundo o autor, técnicas modernizadoras do plantio, como uma maior variedade de produtos plantados, não esgotando o solo, a mecanização da agricultura e um maior desenvolvimento agrícola foram os fatores responsáveis pelo aumento do lucro, fatores estes que independiam do trabalho escravo.

Além do mais, Blackburn retoma a teoria de Williams, afirmando que os ingleses viviam um novo contexto, mais dinâmico, para o qual, o monopólio era um atraso aos interesses econômicos ingleses.

O novo contexto dinâmico mundial, a política do conflito de classes (expressa na Revolução Haitiana) e a as formas pré democráticas de pressão são, segundo

\footnotetext{
${ }^{4}$ Essa ideia é melhor definida pelo autor Christopher L. Brown em seu livro Moral Capital: Foundations of British Abolitionism. Chapel Hill: The University of North Carolina Press, 2006.
} 


\section{COMBATES Epigrafe}

ABOLIÇÃO BRITÂNICA: PARADIGMAS E HISTORIOGRAFIAS

Blackburn, os conceitos chave para compreendermos sistematicamente a abolição da escravidão.

Ora, os argumentos acima referidos nos trazem à tona uma constante luta dialética entre os atores históricos: fazendeiros x comerciantes no que tange à questão do monopólio, escravos x senhores na política do conflito de classes e da liberdade burguesa às custas de uma acumulação exploratória. Nesse ponto, talvez principalmente, Blackburn retoma a obra pioneira de Williams: sua principal ferramenta metodológica é a teoria marxista que, com uma roupagem própria utilizada pelo autor, torna-se seu mecanismo chave para explicar a abolição.

Dessa forma, por meio da análise das obras desses quatro autores, notamos a tendência em relação ao debate em explicar a abolição de duas formas distintas: de uma perspectiva marxista, sendo assim resultante das próprias contradições do sistema capitalista, e de uma forma culturalista, para a qual a existência de uma campanha abolicionista, apenas possível em uma sociedade civil cuja existência se desenvolve à parte do Estado, foi o principal fator do término da escravidão.

\section{REFERÊNCIAS BIBLIOGRÁFICAS}

BLACKBURN, Robin. The american crucible Slavery, Emancipation and Human Rights. Londres: Verso, 2011.

BROWN, Christopher L. Moral Capital: Foundations of British Abolitionism. Chapel Hill: The University of North Carolina Press, 2006.

DRESCHER, Seymour. Abolição: uma história da escravidão e do antiescravismo. Primeira edição: 2009/Tradução: Antonio Penalves Rocha. São Paulo: Editora UNESP, 2011.

JAMES, Cyril Lionel Robert . Os jacobinos negros. Primeira edição: 1938/ Tradução: Afonso Teixeira Filho. São Paulo: Boitempo editorial, 2010.

PADGEN, Anthony. Peoples and Empires: A Short History of European Migration, Exploration, and Conquest, from Greece to the Present. New York: Random House, 2001.

WILLIAMS, Eric. Capitalismo e escravidão. Primeira edição: 1944/Tradução: Denise Bottmann. São Paulo: Companhia das Letras, 2012. 